\title{
Seroprevalence of syphilis amongst pregnant women attending antenatal clinics in a rural hospital in north west Ethiopia
}

\author{
Bereket Azeze, Mesganaw Fantahun, Kidane Gebre Kidan, Tassew Haile
}

\begin{abstract}
Objective-To determine the seroprevalence of syphilis in pregnant women attending antenatal care clinics in a rural hospital in Ethiopia and describe their characteristics so that timely and effective care can be offered.

Subjects-Pregnant women attending antenatal care clinics at a rural hospital. Methods-A cross sectional study was conducted at a rural hospital in north west Ethiopia in September 1994. Data were collected on socio demographic characteristics and past history of sexually transmitted diseases of antenatal care attenders from the records of the hospital. Sera from these pregnant women were examined for syphilis using the VDRL test. VDRL positivity was cross tabulated with socio demographic variables and past history of sexually transmitted diseases.
\end{abstract}

Results-Two hundred and seventy pregnant women were included in the study. Median age of the respondents was $25 \cdot 2$ years. A substantial majority were orthodox Christians $(97 \cdot 4 \%)$ and married $(92 \cdot 6 \%)$. Town dwellers constituted $58 \cdot 2 \%$ of the antenatal care attenders. Only $4.7 \%$ of the women started attending antenatal care clinics during the first trimester. Thirty seven women $(13.7 \%)$ were found to be VDRL positive. Past history of sexually transmitted diseases was significantly associated with VDRL positivity $(\mathrm{p}<0.05)$.

Conclusions-High VDRL positivity rate is observed in this study. Certain risk factors may be responsible for current and past episodes of sexually transmitted diseases. There is a need for improvement of antenatal care activities at different levels of health care. Appropriate strategies should be devised for prevention and control of sexually transmitted diseases in women of reproductive age groups and the general population.

(Genitourin Med 1995;71:347-350)

Keywords: Syphilis; seroprevalence; pregnancy; Ethiopia

\section{Introduction}

Sexually transmitted diseases (STDs) occur all over the world and are common both in developing and in developed countries.
Gonorrhoea, syphilis and now AIDS are the most widely known but there are more than 20 other STDs. Worldwide on average an estimated number of 685000 people are infected with STDs everyday. Every year there are 250 million new cases. ${ }^{1}$ These figures, however, represent a minor part of the problem since a large number go unreported and are likely to be either untreated or improperly treated. Prevalence rates are far higher in developing countries where treatment is less accessible. Among women syphilis prevalence rates may be 10 to 100 times higher in developing countries; gonorrhoea rates may be 10 to 15 times higher. ${ }^{2}$ A review reported a median of $20 \%$ of women attending family planning, antenatal or other clinics in Africa had trichomoniasis. ${ }^{3}$ The prevalence of syphilis in pregnant women in some developing countries ranges from $1 \%$ to $20 \% .{ }^{4}$ The STD epidemic in the developing world is characterised by high rate of complications, alarming rate of antibacterial resistance and interaction with HIV infection. ${ }^{56}$

The impact of syphilis on pregnancy outcome has been well documented in Zambia where abortion, stillbirth, low birth weight and congenital syphilis were strongly associated with infection during pregnancy. ${ }^{7}$ About $40 \%$ of infected pregnancies end up in spontaneous abortion, stillbirth or perinatal deaths. ${ }^{8}$

The impact of STD sequelae goes further than biological damage. Infertility and pregnancy wastage are severe stigmata for women in many societies and may result in divorce and prostitution. ${ }^{9}$

Effective and accessible STD services have made a difference in STD control. In Zambia the national STD programme reduced the number of STD cases at a university teaching hospital from about 18000 in 1985 to about 5000 in $1991 . .^{10}$ The number of spontaneous abortions due to syphilis during pregnancy had also declined.

In Ethiopia STDs ranked sixth among diseases reported by the Ministry of Health facilities, constituting $4.7 \%$ of all cases of communicable diseases in 1986-87. ${ }^{11}$ Syphilis accounted for $15 \%$ of the STDs reported in the years 1986-87. Neglected for many years, programmes to diagnose, treat, and prevent STDs are now becoming an important component of AIDS prevention strategy. The aim of this study was to determine the seroprevalence of syphilis in pregnant women who attend antenatal clinics in a rural hospital in north west Ethiopia and describe its characteristics. This may then allow timely and effective care to be offered. 
Table 1 General characteristics of pregnant women attending antenantal care clinics at Debretabor Hospital, north west Ethiopia, 1994

\begin{tabular}{lrr}
\hline Characteristics & Frequency & Percent \\
\hline Age & & \\
$15-20$ & 65 & $24 \cdot 1$ \\
$21-30$ & 157 & $58 \cdot 1$ \\
$31-45$ & 48 & $17 \cdot 8$ \\
Religion & 263 & \\
Orthodox christian & 7 & $97 \cdot 4$ \\
Moslem & $2 \cdot 6$ \\
Marital status & 250 & \\
Married & 8 & $92 \cdot 6$ \\
Single & 10 & $3 \cdot 0$ \\
Divorced & 2 & $3 \cdot 7$ \\
Widowed & 237 & $0 \cdot 7$ \\
Occupation & 30 & $87 \cdot 8$ \\
Housewife/unemployed & 3 & $11 \cdot 1$ \\
Civil servants & $1 \cdot 1$ \\
Sex workers & 69 & \\
Number of pregnancies & 125 & $26 \cdot 5$ \\
1 & 76 & $46 \cdot 3$ \\
$2-4$ & & $28 \cdot 1$ \\
5-12 & 206 & $76 \cdot 3$ \\
Number of abortions & 42 & $15 \cdot 6$ \\
0 & 22 & $8 \cdot 2$ \\
1 & & \\
2-4 & & \\
\hline
\end{tabular}

\section{Population and methods}

A cross sectional study was conducted in Debretabor rural hospital from June to September 1994, among pregnant women attending antenatal care (ANC) clinics. The hospital has 100 beds and is expected to give service for about 1.9 million people of South Gondar administrative zone, $92 \cdot 2 \%$ of whom are rural dwellers. ANC services are given at the outpatient department of the hospital on a daily basis. On the average 18 pregnant women attended the ANC clinic per day.

A sample size of 271 women was calculated using an appropriate formula ${ }^{12}$ with estimated syphilis prevalence of $18 \%$ (taken from review of records from an adjacent administrative zone, Gondar hospital), confidence level of $95 \%$, acceptable difference of $5 \%$ and contingency $20 \%$. Antenatal cards of all women visiting ANC clinics for the first time during the current pregnancy were reviewed until the required sample size was obtained. Data on socio-demographic characteristics, reproductive history and past history of sexually transmitted diseases were collected. Sera from

Table 3 VDRL status of pregnant women attending ANC clinics at Debretabor Hospital by socio-demographic characteristics, 1994

\begin{tabular}{|c|c|c|c|c|c|}
\hline \multirow[b]{2}{*}{ Characteristics } & \multicolumn{2}{|c|}{$V D R L$ status } & \multirow{2}{*}{$\begin{array}{l}\text { Chi } \\
\text { square }\end{array}$} & \multirow[b]{2}{*}{$P$} & \multirow{2}{*}{$\begin{array}{l}\text { OR } \\
(95 \% C I)\end{array}$} \\
\hline & No & Yes & & & \\
\hline \multicolumn{6}{|l|}{ Age (years) } \\
\hline $15-20$ & 56 & 9 & & & \\
\hline $21-30$ & 140 & 17 & $4 \cdot 5$ & $>0.05$ & \\
\hline $\begin{array}{c}31-45 \\
\text { Marital status }\end{array}$ & 37 & 11 & \\
\hline Married & 218 & 32 & & & \\
\hline Others & 15 & 5 & & $>0.05$ & $2 \cdot 3(0 \cdot 7,7 \cdot 4)$ \\
\hline \multicolumn{6}{|c|}{ Number of pregnancies } \\
\hline 1 & 61 & 8 & & & \\
\hline $2-4$ & 109 & 14 & $2 \cdot 8$ & $>0.05$ & \\
\hline \multirow{2}{*}{\multicolumn{6}{|c|}{ Gestational age at first visit }} \\
\hline & & & & & \\
\hline $\begin{array}{l}\text { First trimester } \\
\text { Second trimester }\end{array}$ & $\begin{array}{l}10 \\
88\end{array}$ & $\begin{array}{r}1 \\
14\end{array}$ & 1.5 & $>0.05$ & \\
\hline Third trimester & 115 & 19 & & & . \\
\hline \multicolumn{6}{|l|}{ Place of residence } \\
\hline Debretabor town & 135 & 22 & & & \\
\hline $\begin{array}{l}\text { Other } \\
\text { Past history of STD }\end{array}$ & 99 & 66 & & $=0.05$ & $2 \cdot 7(1 \cdot 01,8 \cdot 4)$ \\
\hline Past history of STD & 216 & 25 & & & \\
\hline Yes & 17 & 12 & & $<0.05$ & $6 \cdot 1(2 \cdot 4,15 \cdot 6)$ \\
\hline
\end{tabular}

$\mathrm{OR}=$ Odds ratio; $\mathrm{CI}=$ confidence interval.
Table 2 VDRL positivity among pregnant women attending ANC clinics at Debretabor Hospital, north west Ethiopia, 1994

\begin{tabular}{lcc}
\hline VDRL status & Number & Percent \\
\hline Negative & 233 & $86 \cdot 3$ \\
Positive & 37 & $13 \cdot 7$ \\
Total & 270 & $100 \cdot 0$ \\
\hline
\end{tabular}

pregnant women were transported in an ice box to the Gondar College of Medical Sciences hospital laboratory where VDRL test was performed. This serological test detects syphilitic reagin by means of a flocculation reaction, using as antigen cardiolipin and lecthin extracted from beef heart, to which cholesterol is added to enhance antigenic effect. We took a semiquantitative result of +1 and above as positive.

The VDRL antigen used in this study was obtained from Bio Mericus Marcy L'Etiole, France. The false positivity and false negativity rates of this test were estimated as $28 \%$ and $10 \%$ when using the TPHA test as gold standard (Dr. Abraham Assefa. Paper presented at the fifth annual research conference of the Gondar College of Medical Sciences). Data were entered and analysed using EPI INFO Version 5 computer program. Frequency distributions were performed on socio-demographic variables and VDRL status of the study population. VDRL status was then cross tabulated with socio-demographic variables. Odds ratios with $95 \%$ confidence intervals and/or the chi square test were used to assess the association of variables with VDRL status.

\section{Results}

A total of 270 pregnant women were included in the study. General characteristics of the study population are shown in table 1 . The majority of the pregnant women belonged to the age group 21-30 years. Median age of the respondents was 25.2 years. Almost all of the pregnant women in the study $(97.4 \%)$ were orthodox Christians. A substantial majority of the study population $(92 \cdot 6 \%)$ were married and $3 \%$ were never married. Two hundred thirty seven women $(87 \cdot 3 \%)$ were unemployed or housewives. Only three were registered as commercial sex workers. Dwellers of Debretabor town constituted $58.2 \%$ (157) of the antenatal care attenders. The rest came from villages and small rural towns outside Debretabor.

Sixty nine women $(26.5 \%)$ were pregnant for the first time and $76(28 \cdot 1 \%)$ had five or more pregnancies. Sixty six women $(24 \cdot 4 \%)$ had one or more abortions. The majority of the study population $(52.6 \%)$ started attending ANC during the third trimester. Only 4.7\% started attending ANC during the first trimester.

Among the study population 37 women $(13.7 \%)$ were found to be VDRL positive (table 2). Residents of Debretabor town appear to have more than twice the chance of being VDRL positive when compared with dwellers of smaller towns and villages, but the 
difference was not statistically significant $(p=$ 0.054).

As shown in table 3, age, marital status, religion, occupation, number of pregnancies and gestational age at which ANC began were not significantly associated with VDRL status. However, past history of sexually transmitted disease correlated with VDRL positivity $(\mathrm{p}<$ $0.05)$.

\section{Discussion}

The majority of ANC attenders came from urban areas, although $92.2 \%$ of the residents of the administrative zone are rural dwellers. This may be due to problems of accessibility (long walking distance and lack of roads) and less awareness of the services by the rural population. Only $4.7 \%$ of the pregnant women in the study started attending ANC clinics during the first trimester. This contrasts with findings of studies in Addis Ababa, where $26 \%$ of the pregnant women started attending ANC clinics in the first trimester ${ }^{13}$ and elsewhere. ${ }^{14}$ In addition to differences in other socioeconomic characteristics, the reasons mentioned above are perhaps responsible for the small number of women attending ANC clinics early in the course of pregnancy.

VDRL is the only test available for screening syphilis in the area. The false positivity rate is presumably not low. However, many causes for false positivity such as malaria, mycoplasma pneumonia, yaws, pinta, autoimmune reactions and leprosy ${ }^{15}$ are very rare or absent in the study area. High prevalence of syphilis among pregnant women has been reported by a maternity and child health centre in Addis Ababa in $1969^{16}$ and $1977,,^{17}$ being $15.3 \%$ and $10.9 \%$ respectively. In this study we have documented a comparable seroprevalence of syphilis. Reported past history of STDs was significantly associated with seropositivity to syphilis. Previous studies in Ethiopia also showed similar results. ${ }^{18}$

Although the relation is not significant ( $\mathrm{p}=$ 0.054 ) pregnant women living in urban areas had a higher chance of being VDRL positive than rural dwellers. This is in conformity with the results of other studies which reported that the prevalence of STDs is higher in urban centres than rural areas. ${ }^{11} 19$

This study showed no significant association between seroprevalence of syphilis and religion, occupation, and marital status. This might be due to homogeneous nature of the study population with respect to these variables. Orthodox Christians, housewives/ unemployed and married constituted $97 \cdot 4 \%$, $87 \cdot 8 \%$ and $92.6 \%$ of the study population respectively.

The impact of syphilis on pregnancy outcome has been documented in Ethiopia by some studies. Congenital syphilis was the fourth major cause of perinatal mortality in infants with a death rate of $4.9 / 1000$ births $^{20}$; twice as many seropositive mothers as non reactors had still births and spontaneous abortions. ${ }^{21}$
Effective and accessible STD service has made a difference in STD control. ${ }^{11}$ The high prevalence and incidence of STDs in Ethiopia is due to barriers to effective control of STDs which may be attributed to the casual attitude of many Ethiopians toward sexual relations with prostitutes, faith in injectable penicillin as a cure, the common over the counter sale of practically all antibiotics, often the wrong drug or the wrong dose, ${ }^{21}$ and difficulty of control measures based on tracing and treating sexual contacts. A study showed that a delay in seeking effective medical treatment in STD patients at a health centre was attributed to previous visits to traditional healers $(12 \cdot 2 \%)$, local injectors $(16 \cdot 2 \%)$, drug shops $(19 \cdot 2 \%)$ and private clinics $(28 \cdot 6 \%) .^{18}$

The link between HIV infection and STDs that cause genital ulceration is clear. Though not all studies disclosed an association, nine of eleven studies of syphilis and HIV infection found an association. ${ }^{22}$ Syphilis increased the risk of HIV infection threefold to ninefold for heterosexual men. ${ }^{22}$

Prevention and appropriate management of STDs are considered to be cost effective intervention for the prevention of HIV transmissions and the complications of STDs. The high seropositivity rate found in this study demonstrates the need for improvement of ANC clinic activities at different levels of health care. Health education and condom promotion activities should be improved and better organised. Attendance of ANC clinics early in the course of pregnancy has to be encouraged. Appropriate strategies should be designed for prevention and control of sexually transmitted diseases in women of reproductive age groups and the general population.

We are grateful to the staff members of Debretabor hospital for their kind cooperation and Mr. Kassie Molla for carrying out the laboratory work.

1 Khanna J, Vanlook PFA, Griffin PD. Reproductive Health: A key to brighter future. Biennial report 1990-1991. Geneva: World Health Organisation, 1992:171.

2 Wasserheit JN, Holmes KK. Reproductive tract infections. Challenges for international health policy, programmes and research. In: German A, Holmes KK, Piot PJ, Wasserheit JN (eds). Reproductive Tract infections: Global Impact and Priorities for Women's Reproductive Health. New York: Plenum Press. 1992:7-33.

3 Wasserheit JN. The significance and scope of reproductive tract infections among third world women. Int $\mathcal{f}$ Gynec Obstet 1989:(suppl 3):145-68.

4 Brunham RC, Embree JE. Sexually transmitted diseases: current and future dimensions of the problem in the Third World. In: Germaine A, Holmes KK, Piot P, Third World. In: Germaine A, Holmes KK, Piot P,
Wasserheit JN, (eds). Reproductive Tract infections: Global Wasserheit JN, (eds). Reproductive Tract infections: Global Impact and Priorities for Women's Reprod
New York: Plenum Press. 1992:35-58.

5 Buve A, Laga M, Piot P. Sexually transmitted diseases: where are we now? Health Policy and Planning. 1993;8: 277-81.

6 Over M, Piot P. Health sector-priorities review: HIV infection and sexually transmitted diseases. In: Jamson $M$, Mosley WH. (eds). Disease Control Priorities in Developing Countries. New York: Oxford University Press. 1991.

7 Hira SK, Bhat GJ, Chikamata DM, et al. Syphilis intervention in pregnancy: Zambian demonstration project. tion in pregnancy: Zambian

8 De Schryver A, Meheus A. Epidemiology of sexually transmitted diseases. The global picture. Bull WHO 1990 ; 68:639-54

9 Laga M. Epidemiology of sexually transmitted diseases in developing countries. Sexually Transmitted Diseases 1994; 21 (suppl):545-50

10 Sunkutu R, Hira S. STD in Lusaka, Zambia. A review of trend from 1993 to 1991 . (Abstract) Ninth International conference on AIDS/fourth STD World Congress. Berlin, Germany. June 6-11, 1993;2:698. 
11 Ministry of Health of Ethiopia. Comprehensive Health Service Directory. 1986-87 Planning and programming Service Directory. 1986-87 Plannin
bureau. Addis Ababa, 1988:4-18.

12 Colton T. Statistics in Medicine. Little, Brown and Company, 1974:162-3.

13 Fantahun M, Olwit G, Shamebo D. Determinants of antenatal care attendance and preference of site of delivery in Addis Ababa. Ethiop $\mathcal{F}$ Health Dev 1992;6:17-21.

14 Quick J, Greenlick M, Roghman K. Prenatal care and pregnancy outcome in an HMO and general population. A multivariate cohort analysis. Am $₹$ Public Health 1981;71: 381-90.

15 Wilson J, Uncoald E, Isselbacher K, et al (eds). Spirochetal diseases. Harrison's Principles of Intern Medicine. New York: McGraw Hill Inc., 1991:651-61.

16 Larson Y, Larson U. Congenital syphilis. Ethiop Med f 1970;8:163-72.
17 Friedman PS, Wright DJ. Observations on syphilis in Addis Ababa. Prevalence and natural history. $\operatorname{Br} \mathcal{F}$ Vener Dis 1977;53:273-5.

18 Feleke W, Ghidinelli M, Desta S, Yusuf M. Some social features of STD patients in Addis Ababa, Ethiopia. features of STD patients in

19 Chang WP. General review of health and medical problems in Ethiopia. Ethiop Med f 1962;1:9-27.

20 Naeye RL, Teferi N, Marboe CC. Causes of perinatal mortality in an African city. Bull WHO 1977;55:63-9.

21 Gedebou $M$, Tassew $A$. Nesseria gonorrhoea isolates from Addis Ababa: susceptibility to penicillin and tetracycline and frequency of penicillinase producing strains. 7 Trop Med Hyg 1987;90:301-5.

22 Wasserheit $N$. Epidemiological survey: interrelationships between HIV virus and eases. Sexually Transmitted Diseases 1992;19:61-77. 